\title{
Pandemia da COVID-19: repercussōes no quotidiano da família de profissionais de saúde atuantes em unidades emergenciais
}

\author{
The COVID-19 pandemic: repercussions on the daily life of health professionals working in
} emergency units

\section{Pandemia del COVID-19: repercusiones en el cotidiano familiar de profesionales sanitarios actuantes en unidades de urgencia}

\begin{abstract}
Mayckel da Silva Barreto ${ }^{1}$ (D) Angel Braiani Lança Hipolito² (B) Maria Aparecida Lança Hipolito² (1) Fernanda Lise ${ }^{3}$ (D) Cremilde Aparecida Trindade Radovanovic ${ }^{1}$ (1) Sonia Silva Marcon ${ }^{1}$ [D

1. Universidade Estadual de Maringá, Departamento de Enfermagem. Maringá, PR, Brasil.

2. Faculdade de Filosofia, Ciências e Letras de Mandaguari. Mandaguari, PR, Brasil.

3. Universidade Federal de Pelotas, Faculdade de Enfermagem. Pelotas, RS, Brasil.
\end{abstract}

Autor correspondente:

Mayckel da Silva Barreto.

E-mail: mayckelbar@gmail.com.

Recebido em 12/02/2021.

Aprovado em 02/06/2021.

\section{Resumo}

Objetivo: compreender as repercussões da pandemia da COVID-19 no quotidiano de familiares de profissionais de saúde atuantes em unidades de emergência. Métodos: estudo descritivo-exploratório de abordagem qualitativa, realizado com 18 familiares de profissionais de saúde atuantes em duas unidades de emergência localizadas no Sul do Brasil. Os dados foram coletados de setembro a novembro de 2020, mediante entrevistas telefônicas audiogravadas, posteriormente transcritas na íntegra. A análise foi realizada à luz da sociologia compreensiva. Resultados: as repercussões negativas da pandemia no quotidiano dos familiares foram marcadas pelo medo da atuação profissional na linha de frente e pela possibilidade de o familiar se contaminar, levando, por conseguinte, o vírus para os demais membros da família. Porém, paradoxalmente, houve repercussões positivas, como a união dos membros da família e maior aproximação da religiosidade/espiritualidade. Considerações finais e implicações para a prática: identifica-se como relevante o desenvolvimento de estratégias de comunicação para oferecer suporte emocional promover encorajamento, reconhecimento das forças do sistema familiar e, se necessário, educação para que se diminuam as consequências negativas, como o estigma e as desavenças decorrentes dessa experiência.

Palavras-chave: Pandemias; Infecções por Coronavírus; Família; Pessoal de Saúde; Emergências.

\section{Abstract}

Objective: to understand the repercussions of the pandemic of COVID-19 in the daily lives of family members of health professionals working in emergency units. Methods: this is a qualitative descriptive-exploratory study conducted with 18 family members of health professionals working in two emergency units located in the South of Brazil. Data was collected from September to November 2020, through audio-recorded telephone interviews, later transcribed in full. The analysis was conducted in the light of the comprehensive sociology. Results: the negative repercussions of the pandemic in the daily life of family members were marked by the fear of professional performance in the front line and the possibility of the family member getting infected, thus taking the virus to the other members of the family. However, paradoxically, there were positive repercussions, such as the union of the family members and greater closeness to religiosity/spirituality. Final considerations and implications for the practice: the development of communication strategies to offer emotional support, promote encouragement, recognition of the family system's strengths and, if necessary, education to diminish the negative consequences, such as stigma and disagreements arising from this experience, is identified as relevant.

Keywords: Pandemics; Coronavirus Infections; Family; Health Care Personnel; Emergencies.

\section{Resumen}

Objetivo: comprender las repercusiones de la pandemia del COVID-19 en la vida cotidiana de los familiares de los profesionales sanitarios que laboran en las unidades de urgencia. Métodos: estudio descriptivo-exploratorio con abordaje cualitativo, realizado con 18 familiares de profesionales sanitarios que laboran en dos unidades de urgencias ubicadas en el sur de Brasil. Los datos fueron recolectados entre septiembre y noviembre de 2020, a partir de entrevistas telefónicas grabadas en audio posteriormente transcritas íntegramente. El análisis se llevó a cabo a la luz de la sociología comprensiva. Resultados: las repercusiones negativas de la pandemia en la vida cotidiana de los familiares estuvieron marcadas por el miedo a la actividad profesional en primera línea y por la posibilidad de que el familiar se contagie, llevando el virus al resto de familiares. Sin embargo, paradójicamente, hubo repercusiones positivas, como la unión de los miembros de la familia y un acercamiento más próximo a la religiosidad / espiritualidad. Consideraciones finales e implicaciones para la práctica: se identifica como relevante el desarrollo de estrategias de comunicación para ofrecer apoyo emocional, promover el estímulo, el reconocimiento de las fortalezas del grupo familiar y, si es necesario, la educación para reducir las consecuencias negativas, como el estigma y los desacuerdos resultantes de esa experiencia

Palabras clave: Pandemias; Infecciones por Coronavirus; Familia; Personal de Salud; Urgencias. 


\section{INTRODUÇÃO}

A COVID-19, segunda pandemia deste século, apresenta quadro clínico variado, desde infecções por Coronavirus assintomáticas até quadros respiratórios graves. ${ }^{1}$ Dados da Organização Mundial da Saúde (OMS) sugerem que cerca de $20 \%$ dos casos requerem atendimento em unidades de emergência para tratar a dificuldade respiratória. ${ }^{2}$ Por isso, os profissionais de saúde atuantes nos serviços de referência para pacientes com COVID-19 podem ser os primeiros a ficar expostos ao contato com o novo Coronavirus. Isso traz implicações e repercussões no processo de trabalho ${ }^{3-4} \mathrm{e}$, possivelmente, também na vida pessoal e familiar desses profissionais, pois, o medo e a apreensão, sobretudo em relação ao risco de expor-se ao vírus e, por conseguinte, contaminar suas famílias, foi algo enfaticamente relatado por médicos chineses ${ }^{5}$ e enfermeiros brasileiros ${ }^{6}$ que atuavam na linha de frente.

Trabalhar nessa situação pandêmica é exaustivo e psicologicamente perturbador para os profissionais de saúde que atuam nos setores de emergência, desencadeando sintomas de estresse e ansiedade entre eles. ${ }^{7}$ Estudo que analisou 31.769 resumos de publicações relacionadas à COVID-19 identificou que a saúde mental foi o $5^{\circ}$ tema mais abordado nas publicações e, de modo particular, foi a especialidade mais abordada, englobando estudos sobre alterações psicológicas e desenvolvimento de estresse, ansiedade e/ou depressão entre profissionais de saúde. ${ }^{8}$

Durante a pandemia da COVID-19, além dos aspectos relativos aos profissionais, a saúde mental das pessoas em geral tem sido afetada. $\mathrm{O}$ medo de ser infectado por um vírus potencialmente fatal, de rápida disseminação, cujas origens, natureza e evolução ainda não foram completamente estabelecidas, afeta o bem-estar psicológico e emocional de muitas pessoas, ${ }^{9}$ acarretando sinais e sintomas de depressão, ansiedade e estresse na população. ${ }^{10}$

Acredita-se que os efeitos sobre a saúde mental de pessoas que convivem/coabitam com profissionais de saúde da linha de frente possam ser potencializados, pois, é provável que o medo da contaminação seja mais perceptível, diante do contato rotineiro de seus familiares (que são profissionais de saúde) com pacientes com suspeita e/ou confirmação de COVID-19. Inclusive, consta na literatura que os profissionais têm relatado sofrer rejeição social e até discriminação por parte de amigos e familiares. ${ }^{11} \mathrm{E}$ ao considerar que as famílias são sistemas, nos quais a circularidade e reciprocidade influenciam a inter-relação e interdependência entre seus membros, ${ }^{12}$ identifica-se que tais vivências têm potencial para repercutir na dinâmica, no quotidiano e na vida em família.

O quotidiano pode ser considerado o espaço da vida onde estão presentes as maneiras de pensar e agir que se estabelecem no dia a dia, as relações e interações com o outro, o modo de se situar e de se comportar em relação ao outro e ao ambiente, e também as crenças, valores, significados e símbolos que definem o processo de viver em grupo e em família. ${ }^{13,14}$ Portanto, é preciso dar voz aos familiares para se conhecer de que forma a vida quotidiana em família foi impactada pelo fato de um de seus membros atuar em unidade de emergência durante a pandemia da COVID-19, especialmente porque, até onde se sabe, os estudos por ora realizados abordaram somente a perspectiva dos profissionais, ${ }^{6,10-11}$ o que denota a carência na perspectiva do familiar.

Diante do exposto, espera-se que os achados deste estudo possam fornecer informações iniciais para o planejamento de estratégias/intervenções que busquem proporcionar melhor adaptação da família no convívio quotidiano com a atuação profissional de um de seus membros na pandemia. Nesse ínterim, o objetivo do presente estudo foi compreender as repercussões da pandemia da COVID-19 no quotidiano de familiares de profissionais de saúde atuantes em unidades de emergência.

\section{MÉTODO}

Estudo descritivo-exploratório, de abordagem qualitativa, realizado com familiares de profissionais de saúde atuantes nas unidades de emergência de dois municípios de pequeno porte no Norte do estado do Paraná, Brasil, selecionados por conveniência. No início do estudo, segunda quinzena de setembro, um dos municípios já havia registrado 2.273 casos suspeitos de COVID-19, 471 confirmados e oito óbitos; e o outro município, 1.916 casos suspeitos, 594 confirmados e sete óbitos.

As duas unidades são públicas, funcionam como porta-aberta e referência para todos os casos de emergência, incluindo pacientes com problemas respiratórios, durante a pandemia da COVID-19. Ambas são similares no que se refere à estrutura física, processo de trabalho, demanda de usuários (média de 150 atendimentos por dia) e equipe de saúde atuante, constituída por dois enfermeiros, dois médicos e sete técnicos em enfermagem, por plantão.

Para a seleção dos participantes foram adotados os seguintes critérios de inclusão: ser familiar e residir no mesmo domicílio de um profissional de saúde que atuasse em uma das unidades em estudo, e ter 18 anos ou mais. E foram excluídos aqueles que, após três tentativas, em dias e horários diferentes não puderam ser contatados por telefone, e aqueles que, após agendamento para a entrevista, não mais atenderam as ligações dos pesquisadores.

Cabe mencionar que este estudo é parte de uma pesquisa matricial intitulada "Repercussões da pandemia de COVID-19 entre profissionais de saúde de unidades de emergência e seus familiares". Os dados foram coletados nas próprias unidades de emergência dos profissionais de saúde, e estes foram convidados a fornecer, ao final da entrevista, o nome e o telefone de um familiar que atendesse aos critérios de inclusão.

O período de coleta abrangeu os meses de setembro a novembro de 2020, mediante entrevista aberta, a partir de um questionário semiestruturado, constituído de duas partes. A primeira referente a questões sociodemográficas para caracterizar os participantes, e a segunda composta por questões de apoio e da seguinte questão norteadora: De que forma a pandemia da COVID-19 repercutiu no quotidiano de sua família, considerando que você possui um familiar profissional de saúde atuando na linha de frente? 
Os familiares foram entrevistados via telefone, com áudio gravado por meio de um aplicativo. O telefone é considerado uma tecnologia confiável e adequada para o desenvolvimento de pesquisas qualitativas, especialmente durante o período de distanciamento social. ${ }^{15} \mathrm{Em}$ média, as entrevistas duraram entre 10 e 33 minutos e foram conduzidas por duas acadêmicas de enfermagem previamente treinadas. Após as duas primeiras entrevistas, as acadêmicas se reuniram com o orientador, que possui ampla experiência em pesquisa qualitativa, para apresentar os áudios e as transcrições, a fim de que possíveis incongruências/fragilidades no processo de coleta de dados pudessem ser corrigidas inicialmente.

Todas as entrevistas foram transcritas na íntegra, preferencialmente no mesmo dia de sua realização, permitindo a análise fidedigna dos dados, os quais foram ordenados, organizados e categorizados, por meio de um processo sistemático iniciado com diversas leituras dos depoimentos. Todo o processo analítico foi guiado pelos princípios da sociologia compreensiva. ${ }^{13}$ Nesse sentido, buscando-se construir as categorias, foram identificadas as principais palavras-chave destacadas dos depoimentos e, em seguida, agregadas aos temas mais relevantes, ressaltando-se os aspectos comuns e repetitivos dos dados, e até mesmo os diferentes, mas que compunham informações pertinentes para a ampliação do entendimento da realidade estudada. ${ }^{13}$

As exigências éticas preconizadas para pesquisas com seres humanos obedeceram à Resolução 466/2012 e suas complementares. O projeto foi aprovado pelo Comitê Permanente de Ética em Pesquisa com Seres Humanos da Universidade Estadual de Maringá. Antes de iniciar a entrevista, leu-se, na íntegra, o Termo de Consentimento Livre e Esclarecido (TCLE) para os participantes, e, em seguida, solicitou-se que eles manifestassem verbalmente a livre concordância em participar do estudo. Também foi solicitado um endereço eletrônico ou contato de aplicativo de mensagens para que o TCLE, assinado pelos pesquisadores, fosse enviado a cada participante. A fim de garantir o sigilo, os excertos apresentados neste estudo são identificados pelo parentesco com o profissional, seguido de um número arábico, correspondente à ordem de ingresso na pesquisa (Exemplo: Esposa 01).

\section{RESULTADOS}

Dos 18 participantes do estudo, três eram familiares de médicos; seis, de enfermeiros; e nove, de técnicos em enfermagem. Eles tinham idade entre 20 e 61 anos, sendo 14 do sexo feminino, nove cônjuges, três filhos, três mães, duas irmãs e uma tia.

\section{“Uma balança desigual": o paradoxo existente entre vivenciar repercussões negativas e positivas no quotidiano familiar}

Os resultados mostraram que a atuação de um membro da família, na linha de frente, durante a pandemia da COVID-19, repercutiu no quotidiano da família de forma paradoxal e desigual. Isto estava relacionado à ocorrência de mudanças imprevisíveis e abruptas no quotidiano, o que provocou modificações na trajetória de vida, nas atividades sociais e laborais do profissional de saúde, e também do sistema familiar.

De modo paradoxal, havia uma forte tensão entre vivenciar repercussões negativas e positivas. Entre as repercussões negativas estavam o medo, os conflitos, as mudanças e o preconceito vivenciado, relativos ao trabalho do familiar na linha de frente. E entre as repercussões positivas estavam a admiração pelo familiar, a maior proximidade entre os membros da família e o aumento da religiosidade/espiritualidade. Entretanto, as repercussões positivas não eram suficientes para promover o equilíbrio entre a percepção de repercussões negativas e positivas no quotidiano familiar (Figura 1).

\section{Vivenciando repercussões negativas}

Foi possível identificar que os familiares dos profissionais de saúde vivenciaram diversos sentimentos durante a pandemia da COVID-19, entre os quais a preocupação e o medo, especialmente pelo fato de a doença ser desconhecida. Além disso, havia receio de que seu familiar/profissional da saúde se contaminasse durante o trabalho ou trouxesse o vírus para o domicílio e, por conseguinte, contaminasse as demais pessoas da família.

Muito assustadora essa situação! No começo senti um despreparo muito grande, porque essa é uma doença nova, as pessoas não tinham conhecimento ainda (Esposo 12).

Bem estressante nosso quotidiano agora. Cada dia que ele chega em casa, dá muito medo pelo local em que ele está trabalhando, no contato com as pessoas diariamente, principalmente quando a gente ouve casos de que por lá passou alguém contaminado, que alguém testou positivo, esse medo aumenta ainda mais (Esposa 17).

A primeira preocupação foi com ele mesmo, dele contrair esse vírus. Então, o primeiro medo foi dele pegar essa doença. Em consequência, a gente também tem medo de trazer para dentro de casa, porque a gente tem criança pequena (Esposa 06)

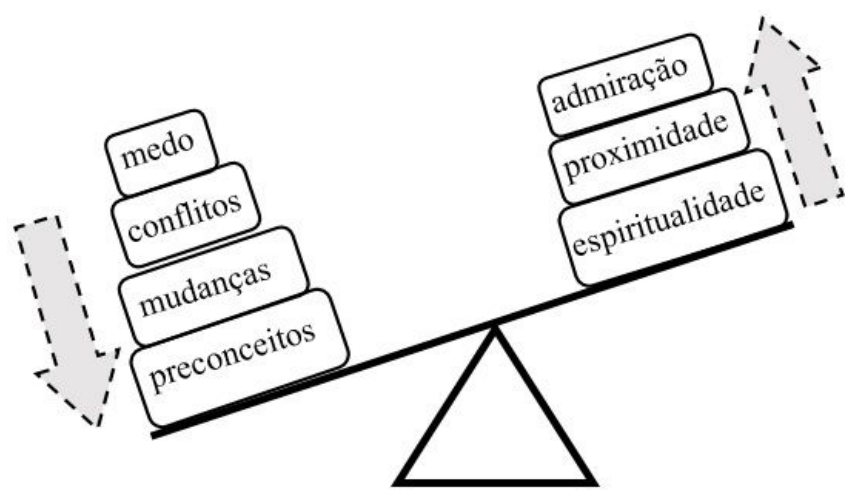

Figura 1. Representação da categoria central: "Uma balança desigual": o paradoxo existente entre vivenciar repercussões negativas e positivas no quotidiano familiar. Fonte: Elaborado pelos autores. 
Em decorrência do medo pela possibilidade de contaminação, alguns entrevistados revelaram o desejo de que o familiar deixasse de exercer a profissão da saúde ou mudasse de emprego, mesmo que momentaneamente, para que o risco fosse minimizado.

Nossos pais ficaram muito apreensivos, sempre falam para ela: "Não tem como você atuar em outro lugar, por exemplo, em um posto de saúde que é menos arriscado?" (Irmã 08).

Eu até comentei com ela, porque fazia pouquinho tempo que tinha começado e eu falei para ela, "Filha, mas logo agora que você vai começar a trabalhar?! Já chega e pega essa situação, com um filho pequeno, amamentando. Por mim ela deixa a enfermagem por um tempo (Mãe 16).

Para muitas famílias foi necessário empregar rearranjos domiciliares a fim de enfrentar a situação de conviver quotidianamente com um profissional de saúde da linha de frente. Por exemplo, alguns entrevistados relataram que foi necessário deixar de visitar familiares mais idosos, o que repercutia no convívio social e na saúde mental dos distintos membros da família.

A gente fica meio preocupado, pois tenho umas tias de idade. Então a gente se vê raramente e quando se vê é com máscara, não é mais como antigamente que estávamos sempre juntos. A gente está sempre esperto, porque ele está em contato direto lá no hospital com pacientes de COVID (Esposa 11).

Houve várias mudanças, exemplo, a minha irmã [que éa profissional de saúde] parou de morar na casa dos meus pais e veio morar com a gente. Agora ela só chega até 0 portão da casa dos nossos pais (Irmã 13).

Eu tenho muito medo! Porque, por mais que o pessoal de saúde fala que usa os equipamentos, faz o teste, a gente não deixa ela chegar perto dos meus pais, ela não faz refeições na casa deles porque são de idade, meu pai é diabético então a gente teve bastante medo e ainda tem! Percebo que todo mundo fica triste com isso, mas fazer o quê? (Tia 18).

Outra repercussão que ocorreu no quotidiano das famílias foi o aumento dos cuidados para evitar a contaminação do ambiente domiciliar e a possível infecção dos familiares. Toda a preocupação, que às vezes pareceu excessiva na percepção do próprio entrevistado, também era responsável por desencadear sentimentos de sofrimento e/ou culpa por parte da família.

A gente não sai mais para lugar nenhum, tomamos mais cuidado com tudo, quando chega do trabalho ele não entra com calçado para dentro de casa, passa álcool em gel, já tira a roupa antes de entrar aqui dentro, corre para o banho, esses cuidados são essenciais (Mãe 05).
Eu já deixava a máquina aberta para ele chegar e colocar toda a roupa dele lá, ia direto para o banheiro e eu ficava em pânico quando ele chegava em casa. No começo fui bastante histérica! Eu não deixava ele se aproximar das crianças, depois que isso acontecia eu ficava até com dó dele, porque via que ele queria abraçar as crianças (Esposa 01).

Alguns entrevistados relataram que o estresse emocional e psicológico, em decorrência do trabalho do familiar, esteve presente na família, e foi o responsável por desencadear conflitos entre os diferentes familiares e impactar a relação e o convívio entre os membros da família extensa.

Tem muito estresse psicológico, houve uma mudança muito grande na nossa vida, envolvendo tudo. Porque tudo que tem que fazer tem que ser muito bem pensado. Tem a questão social, a vida da gente, mas ao mesmo tempo tem o isolamento que precisa ser feito, isso traz uns conflitos dentro da família (Filha 14).

A minha irmã não vem mais aqui por causa do meu marido [que é profissional de saúde], ela vem até o portão me chama e vai embora nem fica aqui, então surge aquele clima estranho. Sinto falta de sentar e conversar com ela, falta daquele tempo que ela tinha de estar aqui (Esposa 02).

Outra repercussão no quotidiano, citada pelos entrevistados, diz respeito à percepção da vivência de situações de preconceito pelo fato de o familiar atuar como profissional de saúde durante a pandemia da COVID-19.

Minha filha sofreu bastante preconceito, por exemplo, a manicure não quis mais atender ela por ser médica, a mulher falou que ela era do grupo de alto risco e, por isso, não quis mais atender (Mãe 03).

Na verdade, teve um pouco de preconceito das pessoas. A família da parte do meu cunhado, não deixou mais minhas sobrinhas irem na casa dos meus sogros, porque a minha esposa frequenta lá. Então, ele deixou de ir por medo dela e fica uma situação bem chata (Esposo 04).

Os familiares demonstraram que as repercussões foram mais intensas no princípio da pandemia, pois, naquele momento, havia maior preocupação, medo e insegurança. Entretanto, com o passar do tempo, a família aprendeu a lidar melhor com a situação, o que diminuiu a percepção de impactos e repercussões no quotidiano da vida em família.

No começo eu fiquei assim bem apavorada, ela chegava e parecia que ela já estava com o vírus, hoje já está mais tranquilo [...] agora parece que a gente sabe lidar um pouco melhor, mas no início parecia que todo mundo ia pegar, 
todo mundo ia ficar doente, todo mundo ia precisar de respirador, porque as notícias eram terríveis (Filha 07).

Foi assustador porque eu tinha que cuidar de mim, mas preocupada com ela [filha que é profissional de saúde], e ela pedia para eu ir embora e eu falava que não ia. Eu falei para ela eu fico com você aqui até o último momento, enquanto você precisar eu estou junto eu não saio, então foi meio aterrorizante, sabe?! Mas, com o tempo a gente vai aprendendo, vai reduzindo, vai melhorando. Mas, principalmente no começo foi muito assustador ninguém podia encostarnela, ninguém podia encostar em mim, se alguém tossisse, até porque engasgou com alguma coisa, a gente achava que poderia ser o coronavirus (Mãe 16).

\section{Vivenciando repercussões positivas}

Mesmo diante de diversas dificuldades enfrentadas em meio às mudanças geradas em decorrência da pandemia da COVID-19, os entrevistados também vivenciaram repercussões positivas no quotidiano. Ainda que reveladas em menor proporção, destaca-se, entre os aspectos positivos, a percepção de admiração pelo trabalho desempenhado pelo familiar durante a pandemia.

Eu me sinto muito orgulhoso do trabalho da minha mãe. Ela vai e enfrenta essa doença. Ela é bem corajosa! Antes não tinha essa percepção (Filho 09).

Eu falava para ela: "mãe é a sua missão, é o seu juramento, agora é a hora que os pacientes mais precisam de você, não pode recuar". Isso me enche de orgulho dela (Filha 07).

A admiração pelo trabalho realizado, e o entendimento de que o familiar necessitava de apoio psicológico da família, fez com que houvesse maior união e respeito entre os membros da família. Alguns destacaram que percebiam a atuação profissional de seu familiar durante a pandemia, como algo relevante para a sociedade.

Nós não vivemos nenhuma situação de preconceito com algum familiar ou amigo. Pelo contrário, aqui houve maior respeito por parte de todos e união dentro da nossa casa. Sabíamos que ela necessitava da nossa força e apoio, pois a barra que ela estava enfrentando era difícil (Irmã 13).

Desde o começo estamos juntos e unidos com ele. Ele está fazendo algo importante para nossa cidade, para as pessoas que vivem aqui, que precisam de atendimento em saúde nesse momento, temos que apoiar ele (Esposa 10).

Também houve relatos de aumento do contato entre os membros da família, utilizando-se as tecnologias de videochamadas e ligações. Essa foi uma importante repercussão positiva no quotidiano do sistema familiar, segundo os participantes.
Ela até evita vir para casa desnecessariamente, nossos contatos aumentaram por via celular e chamadas de vídeo. Então, muito do nosso contato hoje é por telefone, por internet pelo whats app e é duas, três vezes ao dia, muito mais que antes (Mãe 03).

Uma coisa que foi boa é que agora nos falamos mais, seja por mensagem, por ligação, chamada de vídeo, estamos todos mais conectados, queremos toda hora saber se ela está bem! (Tia 18).

Além dessas repercussões positivas identificadas, também foi possível observar que a espiritualidade/religiosidade auxiliou as famílias a vivenciarem as repercussões negativas e os momentos considerados difíceis durante o enfrentamento quotidiano da pandemia da COVID-19.

Enfrentamos isso tudo com muita oração, então a gente sempre depositou nossa confiança em Deus e sempre ele saiu de casa com sentimento de: 'Estou indo cumprir uma missão!' Eu acho que Deus deposita uma bênção diferenciada para esses profissionais. Então a gente enfrenta, essa pandemia e os momentos mais difíceis dessa forma, com muita oração e com sentimento de missão! (Esposa 08).

Eu rezo, sou católica praticante, mas eu não tenho ido à igreja por causa da pandemia mesmo, em casa rezo muito, isso tem fortalecido a nossa família! (Esposa11).

A minha mãe é evangélica, mas já faz cinco meses que ela não consegue ir. Mesmo assim, todo dia de manhã ela escuta as orações, ela faz as preces dela. $A$ espiritualidade sempre mantém o nosso pensamento positivo em relação as coisas, cremos que tudo vai ficar bem (Filha 14).

A gente se apegar a alguma coisa, a uma fé, ajuda a gente conseguir superar, porque você tendo ao que se apegar, você se fortalece mais em acreditar em algo. O nosso apego aqui aumentou bastante depois disso [da pandemia] (Esposo 15).

\section{DISCUSSÃO}

Os resultados mostraram que, durante a pandemia da COVID-19, as famílias dos profissionais de saúde que atuam em unidades de emergência foram fortemente atingidas no aspecto emocional de suas vidas, sendo a percepção de repercussões negativas no quotidiano da família mais frequentemente citada. A princípio, o sofrimento era decorrente de sentimentos de ansiedade e estresse, desencadeados pelo medo relacionado ao risco de contaminação pelo vírus, ao qual o seu familiar estava exposto. Na sequência, pela sensação de incerteza em relação ao risco de contaminação da família e, posteriormente, pelo afastamento do convívio social e familiar. 
Contudo, até o presente momento, a literatura internacional tem destacado apenas as consequências da pandemia da COVID-19 na vida dos profissionais da saúde, ao apontar que a exposição a uma situação de emergência em saúde pública provocou risco ocupacional e sofrimento psicológico devido ao trauma, desvalorização profissional, quarentena e/ou autoisolamento. ${ }^{16-18}$ Contudo, considerase a necessidade de estudos que demonstrem as repercussões também no sistema familiar.

Entende-se que, no contexto da pandemia da COVID-19, é relevante promover a saúde das famílias, pois, estas compartilham emoções e sensações como alegrias e angústias, medo e coragem, aproximação e separação, ${ }^{12}$ e todas as outras possibilidades de duplicidade e dualidade que compõem o jogo da vida desvelado na banalidade do quotidiano. ${ }^{13} \mathrm{~A}$ convergência dessas banalidades de emoções ou de sensações que ocorrem nos atos mais quotidianos, ou que tornam compreensíveis os eventos pontuais, muitas vezes são paradoxais e constituem a dinâmica da vida social. ${ }^{19}$ É na família que a troca acontece de maneira mais abundante e se efetiva, considerando-se que o ser humano necessita de estar-junto-com para poder existir e crescer enquanto ser social. ${ }^{20}$

Trabalhadores da saúde, nos Estados Unidos, identificaram aumento nos níveis de estresse entre os membros de suas famílias. ${ }^{17}$ Esses sentimentos de estresse sensibilizam os indivíduos e podem ser intensificados, em decorrência da mudança repentina na rotina e dos sentimentos experimentados, indo desde insegurança, ambiguidade, estigmatização, ansiedade, insônia até raiva, solidão, frustração e preocupação. ${ }^{21}$ Diante dos sentimentos experimentados, a socialidade faz-se presente nas relações familiares, unindo-os de forma colaborativa para apoiar uns aos outros, mesmo diante da possibilidade de contaminação.

Toda socialidade, aqui entendida como o sistema familiar e a vida quotidiana em família, é marcada por repercussões dos estímulos, sendo que tais repercussões podem ser conflitivas/paradoxais, pois toda harmonia é fundada a partir da diferença e de sentimentos partilhados, mesmo diferentes, contraditórios e plurais. É essa ambivalência assumida que explica a manutenção da socialidade, a presença e o modo de ser dos distintos membros da família. De outra forma, é o que permite completar o sistema familiar, elucidando a estética do ser-estar-junto no mundo, compreendida pela maneira de sentire de experimentar, levando à coesão do sistema familiar, à partilha sentimental de valores, de lugares e ideias. ${ }^{12-13}$

No emaranhado de sentimentos desencadeados pelo fenômeno de se ter um profissional de saúde na família, ao se viver as vicissitudes de uma pandemia como a COVID-19, um misto paradoxal de egoísmo e altruísmo pôde ser identificado nos relatos dos entrevistados. Atitudes altruístas, de empatia e solidariedade, podem ter desencadeado os cuidados minuciosamente pensados para evitar a contaminação dos outros familiares, em casa. Porém, com a proposição de soluções egoístas (por exemplo, ao sugerir o afastamento ou mudança de unidade/local do trabalho do familiar), desvela-se o objetivo de evitar as consequências da contaminação, tanto para o familiar que é profissional quanto para outros membros da família.
É preciso compreender que ser contaminado representa a possibilidade de morrer, e a morte habita a imaginação que circunda o quotidiano das pessoas. As incertezas e o medo da morte se estabelecem em decorrência do fato de a morte se opor à vida. Ambas, vida e morte, coexistem em (im)permanente (des) encontro. Essa harmonia paradoxal evidencia o aspecto duplo da existência humana e aproxima a finitude que rodeia a todos. ${ }^{13}$ Diante da possibilidade da morte, a pandemia proporcionou momentos de ressignificação, efervescência, de manifestações lúdicas e emocionais, por exemplo, manifestações culturais, sociais, políticas e até mesmo de reconhecimento dos profissionais de saúde nas janelas e sacadas. Ademais, possibilitou encontros em redes sociais, fóruns virtuais, lives, todas essas manifestações despertam a atenção para o desejo de se afastar a morte e de as pessoas estarem mais próximas umas das outras. ${ }^{22}$

Os profissionais de saúde que atuam na linha de frente no enfrentamento do novo Coronavirus estão sujeitos ao maior risco de contaminação. Dados da OMS apontam que até setembro de 2020, cerca de 570 mil profissionais da saúde haviam contraído a doença nas Américas, dos quais 307 mil eram brasileiros, representando mais de $54 \%$ do total. ${ }^{23}$ Consequentemente, esses profissionais têm enfrentado o estigma social em torno da possibilidade de constituírem fonte de infecção para seus familiares e grupos sociais. ${ }^{24}$ Por esta razão, alguns membros da família extensa, por medo da contaminação pelo vírus, passaram a apresentar mudanças de comportamento e a evitar contato com o familiar/profissional, o que pode acarretar sentimentos negativos de tristeza, raiva ou frustração. ${ }^{25}$

Em consequência, o isolamento social imposto pelo medo de contaminação com o novo Coronavirus desencadeou impactos negativos na saúde mental dos profissionais da saúde pela impossibilidade de manter contato próximo com familiares e amigos. ${ }^{25-26}$ Esses impactos manifestaram-se mediante sintomas de ansiedade, insônia, angústia, estresse pós-traumático, depressão, medo e frustração, como os relatados na China, entre os trabalhadores de unidades com alto risco de contaminação, ${ }^{26} \mathrm{e}$, nos Estados Unidos, com transtornos relacionados ao abuso de álcool. ${ }^{17}$

Atitudes estigmatizadoras estão relacionadas às crenças não científicas sobre as formas de contaminação, as quais têm se repetido ao redor do mundo e, em alguns casos particulares, expôs situações de preconceito contra profissionais da saúde por parte da comunidade, portanto, uma atitude que pode impactar ainda mais a saúde mental dos profissionais, ${ }^{25}$ e revela o preconceito desse estereótipo, que é um fardo desnecessário, desencadeador de cansaço físico e mental. ${ }^{18} \mathrm{O}$ comportamento estigmatizante está ligado à síndrome de estresse por COVID-19 e pode ser reduzido com intervenções direcionadas, entre as quais orientações e atividades de educação em saúde, que podem contribuir para reduzir o assédio social aos trabalhadores da saúde. ${ }^{24,27}$

Por outro lado, os familiares também relataram comportamentos de cooperação, generosidade e empatia que os conectava à espiritualidade e potencializava o apoio aos profissionais. Estudo realizado com 134 profissionais de saúde da linha de frente, em 
Wuhan, na China, demonstrou que o apoio familiar configurava-se como importante estratégia para promover o bem-estar do profissional, diminuindo a ocorrência de sintomas de ansiedade e depressão. ${ }^{28}$ Além disso, a percepção de maior conexão com a espiritualidade promove a aceitação do destino vivido, que passa a ser afrontado coletivamente pelo grupo social e familiar, emaranhado em suas intersecções culturais, sociais, educacionais, históricas e religiosas. Isso é importante para assegurar ao profissional e a sua família um escudo-protetor eficaz contra as agressões exteriores e o possível esfacelamento da união familiar. ${ }^{13}$

Por sua vez, profissionais de saúde do Reino Unido demonstraram que o apoio da comunidade ao trabalho desempenhado era importante para superar as limitações impostas pela pandemia, ${ }^{24} \mathrm{e}$, nos Estados Unidos, os profissionais perceberam o reconhecimento do seu círculo social, a partir do aumento da percepção de união, de pertencimento e da ampliação do tempo de estar-junto com a família, a partir da redução do ritmo das atividades sociais e do tempo gasto no deslocamento para a escola dos filhos e para o trabalho de outros membros da família. ${ }^{17} \mathrm{~A}$ pandemia trouxe a volta do compartilhamento, da troca, do voluntarismo; uma cultura do sensível, direcionada pela emoção e no tempo presente, em que imperam valores, como o comunitarismo, levando ao estar-junto das pessoas com maior qualidade de sentimento. ${ }^{22}$

Para superar as mudanças quotidianas decorrentes do impacto da carga de estresse desencadeada nas famílias dos profissionais da saúde, as recomendações incluem identificar aquelas em risco e a implementação, pelos serviços de saúde, de medidas imediatas que promovam cuidados para o alívio do estresse e da tensão dos familiares; ${ }^{11,16} \mathrm{e}$, ainda, estimular o afeto e a união entre os indivíduos e suas famílias para o enfrentamento saudável do isolamento social causado pela pandemia da COVID-19. ${ }^{29}$ Nesse contexto, é necessário apoiar as famílias com informações claras e capazes de reduzir a estigmatização; oferecer suporte para o reconhecimento de seus pontos fortes de modo a mitigar gatilhos desencadeadores de desequilíbrio emocional e promover serenidade e encorajamento; reforçar a importância da espiritualidade e da sensação de pertencimento a partir de atividades que promovam o contato visual e/ou auditivos com familiares e amigos; respaldar e reconhecer os esforços realizados na adaptação para reduzir a frustração e promover sentimentos de realização. ${ }^{21}$

\section{CONSIDERAÇÕES FINAIS}

A partir dos resultados deste estudo foi possível compreender as repercussões no quotidiano das famílias de profissionais de saúde atuantes em unidades de emergência durante a pandemia da COVID-19. Compreendeu-se que as repercussões eram paradoxais, marcadas fortemente pela apreensão e medo decorrentes da nova doença e de se ter um familiar na linha de frente; pelas mudanças nas relações familiares e no convívio domiciliar; e pela necessidade de se lidar com o preconceito. Mas, ao mesmo tempo, ainda que em menor proporção, foi identificado aumento na admiração pelo familiar que atuava no enfrentamento da pandemia; melhoria na união dos membros da família, os quais passaram a se comunicar mais, empregando diferentes estratégias tecnológicas; e a maior aproximação do sistema familiar com a religiosidade/ espiritualidade, o que ajudava a enfrentar as repercussões negativas.

Em detrimento dos importantes achados aqui arrolados, este estudo possui limitações: 1 - o fato de as entrevistas terem sido realizadas via telefone pode ter diminuído a interação pesquisador-entrevistado, fazendo com que, em geral, elas fossem mais curtas; 2 - a maioria dos participantes ser do sexo feminino pode ter circunscrito os resultados a uma perspectiva de gênero; 3 - o fato de os locais de atuação dos profissionais serem unidades de pequeno porte, que, apesar de referência para a COVID-19, consistiam em serviços de atendimento inicial, possivelmente influenciou as repercussões quotidianas deles e de seus familiares; 4 - a quarta possível limitação está relacionada à amostragem por conveniência, sujeita ao viés de seleção.

Desse modo, sugere-se que futuras pesquisas sobre a temática considerem abordar familiares do sexo masculino e de profissionais atuantes em serviços de alta complexidade, empregando outras estratégias para a coleta de dados, mesmo que a distância, por exemplo, videoconferências, o que pode aumentar a interação entre o pesquisador e os participantes.

Como contribuições para a prática com famílias e com o objetivo de apoiar o processo de adaptação, desestigmatização e manutenção do equilíbrio emocional, recomenda-se que os serviços de saúde desenvolvam e ofereçam programas de apoio aos seus trabalhadores, incluindo serviço de suporte emocional às suas famílias. Isto é possível a partir do desenvolvimento de um canal de escuta ativa e qualificada, com a oferta de informações claras sobre a evolução da pandemia, e que ensine as famílias a reconhecerem as forças do sistema familiar e a lidar com as situações de estresse e conflitos, diminuindo as consequências negativas, como o estigma e as desavenças decorrentes dessa experiência. Nesse sentido, também é relevante a proposição de ações que possibilitem espaços de troca entre as famílias dos profissionais de saúde, para que possam compartilhar as estratégias saudáveis de convivência e controle dos sentimentos de incerteza, medo, ansiedade, estresse e culpa, de modo que, apoiados por profissionais competentes, possam melhor superar tais desafios.

\section{CONTRIBUIÇÕES DO ESTUDO}

Desenho do estudo. Mayckel da Silva Barreto. Angel Braiani Lança Hipolito. Maria Aparecida Lança Hipolito. Fernanda Lise. Cremilde Aparecida Trindade Radovanovic. Sonia Silva Marcon. Coleta ou produção dos dados. Mayckel da Silva Barreto. Angel Braiani Lança Hipolito. Maria Aparecida Lança Hipolito.

Análise de dados. Mayckel da Silva Barreto. Angel Braiani Lança Hipolito. Maria Aparecida Lança Hipolito. Fernanda Lise.

Cremilde Aparecida Trindade Radovanovic. Sonia Silva Marcon. Interpretação dos resultados. Mayckel da Silva Barreto. Angel Braiani Lança Hipolito. Maria Aparecida Lança Hipolito. Fernanda Lise. Cremilde Aparecida Trindade Radovanovic. Sonia Silva Marcon.

Redação e revisão crítica do manuscrito. Mayckel da Silva Barreto. Angel Braiani Lança Hipolito. Maria Aparecida Lança 
Hipolito. Fernanda Lise. Cremilde Aparecida Trindade Radovanovic. Sonia Silva Marcon.

Aprovação da versão final do artigo. Mayckel da Silva Barreto. Angel Braiani Lança Hipolito. Maria Aparecida Lança Hipolito. Fernanda Lise. Cremilde Aparecida Trindade Radovanovic. Sonia Silva Marcon.

Responsabilidade por todos os aspectos do conteúdo e a integridade do artigo publicado. Mayckel da Silva Barreto. Angel Braiani Lança Hipolito. Maria Aparecida Lança Hipolito. Fernanda Lise. Cremilde Aparecida Trindade Radovanovic. Sonia Silva Marcon.

\section{EDITOR ASSOCIADO}

Antonio José de Almeida Filho (1)

\section{EDITOR CIENTÍFICO}

Ivone Evangelista Cabral (D)

\section{REFERÊNCIAS}

1. Bravo K, Gamarra M, Gonzales S, Lecca D, Martínez A, Mendonza $M$ et al. Nivel de conocimientos sobre la influenza a H1N1 en los trabajadores de salud del Hospital Nacional Arzobispo Loayza, Perú. Rev. Peru. Epidemiol [Internet]. 2009[citado 2021 Jan 14];13(2):1-7. Disponível em: https://www.redalyc.org/pdf/2031/203120363003.pdf.

2. Brasil. Ministério da Saúde. Coronavirus (Covid-19) clinical management protocol in primary health care: version 9. Brasília, DF;2020. Disponível em: https://portaldeboaspraticas.iff.fiocruz.br/biblioteca/protocolo-demanejo-clinico-docoronavirus-covid-19-na-atencao-primaria-a-saude/

3. Belarmino AC, Rodrigues MENG, Anjos SJSB, Ferreira Júnior AR. Collaborative practices from health care teams to face the Covid-19 pandemic. Rev Bras Enferm. 2020;73(Suppl. 2):e20200470. http:// dx.doi.org/10.1590/0034-7167-2020-0470. PMid:33111780.

4. Teixeira AC, Pereira R, Silva JAP. Facing COVID-19: experience report from a portuguese intensive care unit. Rev. Parana Enferm [Internet]. 2020 [citado 2021 Jan 04]; 3(1):82-90. Disponível em: http://seer.fafiman. br/index.php/REPEN/article/download/599/553

5. Kang L, Li Y, Hu S, Chen M, Yang C, Yang BX et al. The mental health of medical workers in Wuhan, China dealing with the 2019 novel coronavírus. Lancet Psychiatry. 2020;7(3):e14. http://dx.doi.org/10.1016/ S2215-0366(20)30047-X. PMid:32035030.

6. Góes FGB, Silva ACSS, Santos AST, Pereira-Ávila FMV, Silva LJ, Silva LF et al. Challenges faced by pediatric nursing workers in the face of the COVID-19 pandemic. Rev. Latino-Am. Enfermagem. 2020;28:e3367. http://dx.doi.org/10.1590/1518-8345.4550.3367. PMid:32901774.

7. Dal'Bosco EB, Floriano LSM, Skupien SV, Arcaro G, Martins AR, Anselmo ACC. A saúde mental da enfermagem no enfrentamento da COVID-19 em um hospital universitário regional. Rev Bras Enferm. 2020;73(Suppl. 2):e20200434. http://dx.doi.org/10.1590/0034-71672020-0434. PMid:32667576.

8. Baratieri T, Lentsck MH, Peres CK, Pitilin EB. Modeling of research topics on the new coronavirus: application of latent dirichlet allocation. Ciênc. Cuid. Saúde. 2021;20:e-56403. https://doi.org/10.4025/cienccuidsaude. v20i0.56403.

9. Asmundson GJG, Taylor S. Coronaphobia: Fear and the 2019-nCoV outbreak. J Anxiety Disord. 2020;70:102196. http://dx.doi.org/10.1016/j. janxdis.2020.102196. PMid:32078967.

10. Wang H, Liu Y, Hu K, Zhang M, Du M, Huang H et al. Healthcare workers' stress when caring for COVID-19 patients: An altruistic perspective. Nurs Ethics. 2020;27(7):1490-500. http://dx.doi.org/10.1177/0969733020934146. PMid:32662326
11. Ornell F, Schuch JB, Sordi AO, Kessler FHP."Pandemic fear" and COVID-19: mental health burden and strategies. Braz J Psychiatry. 2020;42(3):232-5. http://dx.doi.org/10.1590/1516-4446-2020-0008. PMid:32267343.

12. Wright LM, Leahey M. Nurses and families: A guide to family assessment and intervention. 7th ed. Philadelphia: Davis; 2019.

13. Maffesoli M. O conhecimento comum: introdução à sociologia compreensiva. Tradução de Aluízio Ramos Trinta. Porto Alegre: Sulina; 2010.

14. Nitschke RG. Pensando o nosso quotidiano contemporâneo e a promoção de famílias saudáveis. Ciênc Cuidado Saúde. 2007;6(Suppl. 1):24-6.

15. Greenhalgh T, Koh GCH, Car J. Covid-19: a remote assessment in primary care. Rev Bras Med Fam Comunidade. 2020;15(42):2461. http://dx.doi.org/10.5712/rbmfc15(42)2461. PMid:32213507.

16. Wu PE, Styra R, Gold WL. Mitigating the psychological effects of COVID-19 on health care workers. CMAJ. 2020;192(17):E459-60. http://dx.doi.org/10.1503/cmaj.200519. PMid:32295761.

17. Hennein R, Lowe S. A hybrid inductive-abductive analysis of health workers' experiences and wellbeing during the COVID-19 pandemic in the United States. PLoS One. 2020;15(10):e0240646. http://dx.doi. org/10.1371/journal.pone.0240646. PMid:33104711.

18. Lai J, Ma S, Wang Y, Cai Z, Hu J, Wei $\mathrm{N}$ et al. Factors associated with mental health outcomes among health care workers exposed to coronavirus disease 2019. JAMA Netw Open. 2019;3(3):e203976. http:// dx.doi.org/10.1001/jamanetworkopen.2020.3976. PMid:32202646.

19. Maffesoli M. A conquista do presente: por uma sociologia da vida cotidiana. Natal, RN: Ed. Argos; 2001.

20. Maffesoli M. Algumas notas edificantes e curiosas escritas para o uso daqueles que querem pensar o mundo tal como ele é. Rev Famecos 2011;1(2):312-26. http://dx.doi.org/10.15448/1980-3729.2011.2.9463.

21. International Family Nursing Association. COVID-19 Pandemic and Family Nursing: IFNA President and President-Elect Offer a Message to Members [Internet]. Pittsburgh; 2020 [citado 2021 Jan 21]. Disponível em: https://internationalfamilynursing.org/2020/03/27/covid-19-pandemicifna-president-and-ifnapresident-elect-offer-a-message-to-members/

22. Maffesoli M. Sanitary crisis, civilizational crisis. Space Cult. 2020;23(3):2269. http://dx.doi.org/10.1177/1206331220938617.

23. Organização Mundial da Saúde. Cerca de 570 mil profissionais de saúde se infectaram e 2,5 mil morreram por COVID-19 nas Américas [Internet]. Brasília: OPAS; 2020 [citado 2021 Jan 21]. Disponível em: https://www.paho.org/bra/index.php?option=com content\&view=artic le\&id=6270:cerca-de-570-mil-profissionais-de-saude-se-infectarame-2-5-mil-morreram-por-covid-19-nas-americas\&ltemid=812\#: :tex$\mathrm{t}=\% 22$ Nossos $\% 20$ dados $\% 20$ mostram $\% 20$ que $\% 20$ quase,desta $\% 20$ pandemia\%20n\%C3\%A30\%20tem\%20precedentes.

24. Bagcchi S. Stigma during the COVID-19 pandemic. Lancet Infect Dis 2020;20(7):782. http://dx.doi.org/10.1016/S1473-3099(20)30498-9. PMid:32592670.

25. Javed B, Sarwer A, Soto EB, Mashwani ZUR. The coronavirus (COVID -19) pandemic's impact on mental health. Int J Health Plann Manage. 2020;35(5):993-6. http://dx.doi.org/10.1002/hpm.3008. PMid:32567725.

26. Xiang YT, Yang Y, Li W, Zhang L, Zhang Q, Cheung T et al. Timely mental health care for the 2019 novel coronavirus outbreak is urgently needed. Lancet Psychiatry. 2020;7(3):228-9. http://dx.doi.org/10.1016/ S2215-0366(20)30046-8. PMid:32032543.

27. Taylor S, Landry CA, Rachor GS, Paluszek MM, Asmundson GJ. Fear and avoidance of healthcare workers: An important, under-recognized form of stigmatization during the COVID-19 pandemic. J Anxiety Disord. 2020;75:102289. http://dx.doi.org/10.1016/j.janxdis.2020.102289. PMid:32853884.

28. Du J, Dong L, Wang T, Yuan C, Fu R, Zhang L et al. Psychological symptoms among frontline healthcare workers during COVID-19 outbreak in Wuhan. Gen Hosp Psychiatry. 2020;67:144-5. http://dx.doi. org/10.1016/j.genhosppsych.2020.03.011. PMid:32381270.

29. Lise F, Neves JL, Oliveira NP, Sena LR, Schwartz E. Abordagem da enfermagem às famílias no enfrentamento do distanciamento social e do Novo Coronavirus. Enferm. foco. 2020;11(12):219-226. 